\title{
A comunicação científica e o movimento de acesso livre ao conhecimento*
}

\section{Suzana Pinheiro Machado Mueller}

$\mathrm{PhD}$ in Information Studies (University of Sheffield, UK. (1982).

Professora titular. Departamento de Ciência da Informação.

Universidade de Brasília.

E-mail: mueller@unb.br

\section{Resumo}

Trata do problema da aceitação, pela comunidade científica, dos periódicos eletrônicos de acesso aberto. Propõe a questão da legitimação e legitimidade dessas publicações como elemento essencial para sua plena aceitação. Define legitimação e legitimidade com base em alguns autores. Mostra como a crise dos periódicos da década de 1980 detonou o início do processo de aceitação dos periódicos eletrônicos e como agora o movimento pelo acesso aberto vem crescendo e, ao mesmo tempo, enfrentando barreiras do preconceito e interesses. Nota, como grandes empecilhos ao pleno reconhecimento, o processo de avaliação pelos pares, interesses de segmentos da comunidade científica $e$ interesses das editoras comerciais. Conclui notando o fortalecimento do conceito da necessidade da avaliação prévia e amadurecimento nas idéias pioneiras de democratização na publicação do conhecimento científico e avanço na aceitação das idéias. Mas reconhece também o papel das editoras e das elites de cada área como os poderes com maior influência na direção e velocidade do percurso das publicações eletrônicas de acesso livre e sua incorporação ao sistema de comunicação científica como canais legítimos.

\section{Palavras-chave}

Acesso livre ao conhecimento científico. Arquivos abertos. Comunicação científica de acesso livre. Legitimação e legitimidade das publicações eletrônicas.

\section{Scientific communication and the open access movement in scholarly publishing}

\begin{abstract}
The open access movement acceptance by the scientific community has met many barriers. It is argued that understanding the processes of legitimation and legitimacy is essential to the issue. Bringing forward some definition by scholars on the subject of legitimation and legitimacy, the article tries to show how the periodical crisis of the 80's triggered the processes of acceptance of the electronic periodical. The open access movement followed, and today it is currently trying to overcome barriers of prejudice and vested interests. It concludes by noting the strengthening of the concept of the necessity of peer review, but also the maturing of the movement, today less utopian and more realistic. It recognizes the role of the publishers and of segments of the scientific communities as the main forces in shaping scientific communication system and allowing advances of the open access channels towards legitimacy.
\end{abstract}

\section{Keywords}

Open access movement. Open archives. Legitimation and legitimacy of open access scientific publications.

\section{INTRODUÇÃO}

O movimento para acesso livre ao conhecimento científico pode ser considerado como o fato mais interessante e talvez importante de nossa época no que se refere à comunicação científica. Ao mesmo tempo, este movimento representa enorme desafio para a comunidade científica, à medida que, quanto mais amplo o seu sucesso, mais radical será a mudança provocada no sistema tradicional e profundamente arraigado de comunicação do conhecimento científico.

A comunidade científica concedeu às revistas indexadas e arbitradas (com peer review) o status de canais preferenciais para a certificação do conhecimento científico e para a comunicação autorizada da ciência e deu-lhe, ainda, a atribuição de confirmar a autoria da descoberta científica. As revistas indexadas estão, dessa forma, no centro do sistema tradicional de comunicação científica. Mas é consenso, também, entre os membros da comunidade, que este sistema está longe de perfeito. Além dos problemas ligados ao processo da publicação dos artigos, o custo extremamente alto de manutenção de coleções atualizadas pelas bibliotecas provoca dificuldade de acesso para o leitor.

Ao surgirem e ganharem formas inovadoras, a partir da década de 90, as publicações científicas eletrônicas despertaram esperanças, em muitos pesquisadores, de uma mudança radical no sistema tradicional de comunicação científica. Assim como os utopistas da Renascença, alguns sonharam com um novo sistema de comunicação, no qual o acesso a todo conhecimento científico se tornaria universal e sem barreiras. Especialmente nos países mais afastados dos principais centros produtores, surgiu a esperança não só de acesso ao que era produzido fora, mas também que a produção local teria maior visibilidade e penetração internacional. Porém, passados cerca de 15 anos desde o surgimento das

* Algumas partes deste texto foram adaptadas da palestra intitulada Reflexões sobre o processo de legitimação das publicações eletrônicas na comunicação científica, proferida no evento CONFERÊNCIA IBERO-AMERICANA SOBRE PUBLICAÇÕES ELETRÔNICAS NO CONTEXTO DA COMUNICAÇÃ CIENTÍFICA - CIPECC, 1., realizada em Brasília, de 25 a 28 de abril de 2006. e publicada nos Anais do Evento. 


\section{Suzana Pinheiro Machado Mueller}

primeiras publicações eletrônicas, vemos que, assim como nas utopias, a realidade se mostra diferente do sonho. As bibliotecas universitárias nem sempre conseguem renovar suas assinaturas de revistas internacionais, eletrônicas ou não, e os pesquisadores dos países não centrais ainda enfrentam algumas dificuldades para publicar nos títulos principais de suas áreas ou ter sua produção reconhecida internacionalmente. Em retrospecto, as expectativas que então surgiram com as possibilidades da tecnologia talvez pareçam hoje um tanto ingênuas, um sonho utópico de socialização do conhecimento, sem fronteiras e preconceitos.

Neste artigo, pretende-se fazer algumas reflexões sobre pontos considerados relevantes para a questão. A posição adotada neste trabalho considera que as publicações de acesso livre ainda não conseguiram obter o status de plena legitimidade na crença das comunidades científicas. A argumentação será dirigida para reforçar a tese de que a tradição das práticas da comunicação científica e a noção de legitimidade que prevalece na comunidade científica, aliadas e reforçadas pelos interesses das grandes editoras, vêm influenciando e retardando a trajetória das publicações eletrônicas e do movimento rumo ao acesso livre ao conhecimento científico.

Inicialmente, o texto apresenta e comenta algumas noções básicas sobre legitimação e legitimidade, na sociedade como um todo e na ciência, de forma a estabelecer as bases para a argumentação. Focaliza, em seguida, aspectos da comunidade científica e de seu sistema de comunicação. Por último, faz considerações sobre o movimento do acesso livre ao conhecimento científico nesse contexto.

\section{OS CONCEITOS DE LEGITIMAÇÃO E LEGITIMIDADE}

Os fenômenos legitimação e legitimidade perpassam todas as atividades sociais. Como objeto de estudo tem sido de interesse de várias áreas, especialmente direito, sociologia, psicologia e ciência política. Entre os diversos autores que se preocuparam com o tema, ao longo do tempo, estão desde Platão e Aristóteles a Weber, Parsons, Bobbio, Habermas, Lyotard, Foucault, Luhmann, Zelditch. Embora cada autor trate o tema a partir de perspectivas diferentes, há um entendimento comum a todos, que se percebe quando associam os conceitos legitimação e legitimidade a poder, autoridade, consenso, crenças, normas e leis, conformidade, estabilidade, controle social, desvio, repressão.
Foram selecionados para este trabalho e serão comentados, a seguir, cinco textos de autores que, ao definirem os conceitos legitimação e legitimidade, ressaltaram pontos considerados relevantes para a reflexão que se pretende. $O$ critério da escolha foi dirigido pela intenção de construir um pano de fundo contra o qual, mais adiante, será considerado o caso específico do movimento pelo acesso aberto no sistema tradicional de comunicação científica. São primeiramente expostas e comentadas definições que se referem às sociedades em geral e a aspectos legais nessas sociedades. A essas, seguem definições propostas por autores que tinham em mente o contexto específico da ciência.

O primeiro ponto que importa para a presente discussão diz respeito à relação de dependência entre os conceitos de legitimidade e consenso. Esse assunto foi tratado por Zelditch, que enfatiza o consenso como elemento essencial para haver legitimidade. Segundo o autor, o pressuposto de que o consenso é condição necessária à legitimação tem sido fundamental para todas as teorias de legitimidade. Zelditch (2001, p.9) define legitimação como um "processo que conforma o inaceitável às normas, valores, práticas e procedimentos aceitáveis". Portanto, por definição, legitimidade depende de consenso.

Partindo do pressuposto de que o consenso confere legitimidade a um poder e trabalhando sobre as definições dadas pelo Dictionnaire Encyclopédique de Théorie et de Sociologie du Droit ARNAUD, apud Bissot (2002) relaciona "a medida de legitimidade de um poder ao reconhecimento que lhe conferem aqueles que lhe são sujeitos". Para este autor, um poder será considerado legítimo quando houver equilíbrio entre a forma como o poder é exercido pela autoridade e a noção que a sociedade tem de como esse poder deva ser exercido. Ainda de acordo com Bissot, a noção de legitimidade é eminentemente subjetiva e própria de uma época e sociedade, de uma cultura e um lugar. O sentimento de legitimidade em relação a um poder, quando existe entre os sujeitos de uma sociedade, induz esses sujeitos à conformidade àquele poder.

Lidando também com a conformidade e consenso, Tyler (2006) afirma que o reconhecimento da legitimidade induz as pessoas a voluntariamente se comportarem de acordo com as normas. Tyler (2006) argumenta que esse compromisso social voluntário é decorrente da legitimação da autoridade e define legitimidade como a "crença que autoridades, instituições e organizações sociais são corretas, adequadas e justas, levando as pessoas a se sentirem obrigadas a obedecer àquelas autoridades, instituições e organizações sociais". Segundo Tyler, só assim podemos explicar por que aceitamos injustiças e 
diferenças sociais tão grandes ou a autoridade de uns sobre outros.

A legitimação de uma determinada situação se refere à característica dessa situação ser considerada legítima porque é vista como sendo correta ou apropriada. Assim, por exemplo, um conjunto de crenças que existe em uma sociedade pode explicar por que tal sociedade julga corretas ou aceitáveis diferenças na distribuição de autoridade, poder, status e riqueza. A legitimação tem como conseqüência encorajar as pessoas a aceitarem essas diferenças. Considerando a autoridade individual ou da instituição, legitimidade é uma propriedade que, quando possuída, leva as pessoas a voluntariamente aceitarem decisões, regras e arranjos sociais. (TYLER, 2006).

A mesma noção expressa por esses autores, de que a crença na legitimidade de um poder é baseada em consenso e provoca conformidade, obediência voluntária e aceitação social de diferenças na distribuição de poder e autoridade, é percebida e desenvolvida por Lyotard. Em seu texto sobre a pós-modernidade, Lyotard amplia os conceitos legitimação e legitimidade para além das questões estritamente legais, reconhecendo-as presentes também em outros níveis da sociedade, inclusive nas comunidades científicas. No trecho citado abaixo, Lyotard (1984, p.8) faz um paralelo entre a autoridade legitimada do poder civil e o fenômeno da legitimação do conhecimento científico:

Eu uso o termo [legitimação] em um sentido mais amplo do que tem sido usado pelos teóricos alemães contemporâneos em sua discussão sobre a questão da autoridade. Consideremos, como exemplo, qualquer lei civil: ela estipula que uma dada categoria de cidadão deva desempenhar determinado tipo de ação. Legitimação é o processo pelo qual um legislador é autorizado a promulgar esta lei como uma norma. Agora consideremos o exemplo de uma afirmação científica: ela está sujeita à regra que estabelece que uma afirmação deva preencher um dado conjunto de condições para ser aceita como científica. Neste caso, legitimação é o processo pelo qual um "legislador" trabalhando com discurso científico é autorizado a prescrever as condições (em geral, condições relacionadas à consistência interna e verificação experimental) que determinam se uma afirmação poderá ser incluída naquele discurso pela comunidade científica (LYOTARD, 1984.)

Ci. Inf., Brasília, v. 35, n. 2, p. 27-38, maio/ago. 2006
Shawver (1998), comentando esse texto de Lyotard, chama a atenção para o fato de o autor colocar a palavra "legislador" entre aspas, entendendo com isso que Lyotard está conferindo o status de legislador a qualquer pessoa a quem é conferida a capacidade de decidir o que uma norma estabelece e em qualquer contexto. $\bigcirc$ próprio Lyotard, referindo-se especificamente à questão da legitimidade da ciência, ressalta sua ligação indissociável e histórica, "estabelecida desde o tempo de Platão", à questão da legitimação do legislador. Do seu ponto de vista, o direito de decidir o que é verdade não é independente do direito de decidir o que é justo ou ético. Conhecimento e poder são, para ele, dois lados de uma mesma questão: quem decide o que é conhecimento, e quem sabe o que precisa ser decidido na era do computador, seria, para Lyotard (que escreveu isso em 1979), "mais do que nunca uma questão de governo". (LYOTARD, 1984).

As idéias de Lyotard parecem ter inspirado a última definição selecionada para este texto, retirada da Encyclopedia of Marxism (ENCYCLOPEDIA... 1999), um dicionário marxista on-line. Agora, o contexto é especificamente a comunidade científica. A definição introduz também a questão de interesses sociais e comerciais na produção do conhecimento científico, elaborando e ampliando a idéia de Lyotard:

Legitimação significa, literalmente, tornar legal, mas a teoria social reconhece que os processos pelo qual uma ação passa a ser considerada legítima são bem mais amplos que o sistema legal e são fundamentais não apenas para as relações de poder em uma sociedade, mas também para as suas relações de produção, ideologia e sistema de crenças. Por exemplo, quais os meios que tornam uma teoria científica 'legítima'? Seria o autor um "cientista" legitimado por uma instituição que, por sua vez, foi legitimada pelo Estado? A teoria foi publicada em um periódico "científico" e foi "avaliada pelos pares"? Essa teoria se encaixa com outras teorias que já foram carimbadas como legítimas, e assim por diante? Além de tudo isso, essa teoria jamais veria a luz do dia se, em primeiro lugar, não tivesse havido financiamento para a pesquisa, o que envolve uma série de processos de legitimação e conhecidos interesses sociais. O conhecimento, hoje, está sendo comercializado como jamais foi (LEGITIMATION... 19939-5005).

Concluindo e consolidando a visão dos autores examinados, entendemos que legitimação significa tornar 


\section{Suzana Pinheiro Machado Mueller}

legal e que, embora seja um termo originalmente usado no contexto de sistemas legais, os processos que levam uma ação a ser considerada legítima extrapolam os sistemas legais, e esse é o caso da comunicação científica. Legitimação exige consenso. Legitimidade é a crença que autoridades, instituições e organizações sociais são corretas, adequadas e justas, por isso devem ser respeitadas e aceitas. A crença que autoridades e instituições são legítimas compele as pessoas a aceitar suas decisões e a voluntariamente obedecê-las. Legitimidade é um conceito eminentemente subjetivo, restrito a uma época e lugar e provoca a conformidade. No campo da ciência, legitimação é o processo pelo qual o "legislador" encarregado de zelar pelo discurso científico é autorizado, pela comunidade científica, a prescrever as condições que estabelecem se determinado conhecimento pode ser considerado científico.

Tendo como pano de fundo esses conceitos de legitimação e legitimidade da ciência, será discutido, a seguir, o contexto onde o movimento de acesso aberto ao conhecimento científico ocorre: o sistema de comunicação científica e a comunidade científica.

\section{O SISTEMA DE COMUNICAÇÃO CIENTÍFICA E A COMUNIDADE CIENTÍFICA}

A íntima relação entre "comunicação científica" e "comunidade científica" fica bem clara na afirmação de Lyman (1997), para quem o sistema de comunicação científica é a infra-estrutura da comunidade científica. Assim, para entendermos o sistema de comunicação científica e movimento pelo acesso aberto, temos de considerar o contexto em que o sistema opera, a comunidade científica.

Os vários autores que têm estudado as comunidades científicas, tais como Merton, Zuckerman, Kuhn, Bourdieu, Latour, Fourez, Ziman, entre tantos outros, reconhecem a estrutura hierárquica que as caracteriza. Em qualquer nível que se considere, há uma elite de poucos membros que detém a autoridade, ancorada em prestígio individual, conquistada por mérito reconhecido pelos demais, geralmente ao longo de uma carreira.

Citando Fourez (1995, p. 95), que se referia às ciências naturais, mas cuja observação pode ser ampliada para outras áreas da ciência,

[...] quando examinamos de perto, a "comunidade científica" revela-se como um pequeno mundo bastante estruturado. Há os "grandes" experimentadores de laboratório, que possuem relativamente bastante poder, depois outros que são como "operários especializados", e enfim existem os "proletários de laboratórios" os assistentes de laboratório (aspas do autor).

Quem são os "grandes", essas pessoas em quem os membros das comunidades científicas reconhecem o poder de avaliá-los, a quem foi conferida a autoridade para decidir quem será aceito nas melhores universidades, quais artigos serão aceitos nas revistas mais prestigiadas, quem receberá prêmios, bolsas e financiamentos ou quem será admitido nas sociedades científicas? Cole (1983) os identifica como os membros de comissões avaliadoras (como as comissões editoriais ou as bancas examinadoras de processos de seleção, por exemplo), os cientistas mais eminentes, as chamadas "estrelas" de cada área. Eles são aqueles a quem Lyotard (1984) se refere como os "legisladores" encarregados do discurso científico. Mas a hierarquia também está presente entre os membros dessa elite, pois nem todas as "estrelas" têm a mesma grandeza e as diversas comissões não gozam do mesmo prestígio. Até mesmo entre os membros de uma mesma comissão, nos processos de avaliação, algumas opiniões às vezes contam mais que outras, algumas opiniões influenciam mais que outras. Todos, no entanto, devem ter sua autoridade legitimada pelos colegas, para que suas decisões sejam aceitas.

Assim como há hierarquia entre indivíduos que formam as comunidades científicas, há também hierarquia entre os diversos tipos de veículos que podem ser usados para comunicar o conhecimento científico - por exemplo, periódico, livro, trabalho de congresso. Embora varie conforme a área, o periódico indexado costuma ser o veículo mais prestigiado. Mas, entre os periódicos indexados, também há uma elite: os títulos mais prestigiosos. Da mesma forma, atribuem-se graus diferentes de prestígio às editoras que os publicam, à língua que usam e às bases de dados que os indexam. Aqueles periódicos que estão no topo de sua área têm freqüentemente como editores e avaliadores as "estrelas" desta área.

A posição de prestígio dos cientistas e dos periódicos é mantida e sustentada por um sistema de avaliação baseado em vários indicadores, tais como quantidade de publicações, índices de citação e visibilidade internacional. Entre os indicadores mais utilizados, mas nem por isso isentos de muitas críticas e insatisfações, estão as citações e os diversos índices derivados de sua contagem, especialmente o fator de impacto, que é uma medida da penetração ou visibilidade. O Institute for 
Scientific Information (ISI)* é praticamente a única fonte universalmente "legitimada" pela comunidade internacional para estabelecer não apenas os dados de citação e indicadores, mas também as fórmulas utilizadas para calcular tais indicadores. Na prática, portanto, o ISI vem estabelecendo, de fato, os parâmetros utilizados para classificação de autores e periódicos. Apesar de adotados por muitas instituições e países ao redor do mundo, os índices da ISI são também muito contestados, porque seus métodos de seleção privilegiariam determinados periódicos por sua origem. Já foram apresentadas várias tentativas de mudanças e novas propostas de indicadores para avaliação que poderiam substituir ou pelo menos diminuir a influência do ISI, mas sem sucesso. Embora mais importante para as áreas das ciências físicas e naturais, a influência dos indicadores produzidos pelo ISI é reconhecida por todas as áreas e a inclusão de periódicos eletrônicos de acesso aberto em sua lista de periódicos examinados certamente seria um marco formidável de aceitação.

A comunidade científica não existe em um vácuo social, mas é um dos muitos grupos sociais que compõem a sociedade contemporânea, estando, portanto, sujeita às forças presentes nessa sociedade. Assim, permeando e influenciando a estrutura de seu intrincado sistema de comunicação, há interesses financeiros das editoras que dominam o mercado de periódicos, há os interesses das instituições de pesquisa e universidades que lutam por prestígio e financiamento, há interesses nacionais, políticos e econômicos que buscam o desenvolvimento e prestígio nacional e há o interesse pessoal dos pesquisadores, tanto daqueles que já ocupam os lugares mais altos na hierarquia - e que desejam lá permanecer -, quanto daqueles que estão em ascensão e disputam lugares mais altos e também os marginalizados, para quem mudanças seriam, talvez, favoráveis.

\section{A CRISE DOS PERIÓDICOS E A PROMESSA DO ACESSO LIVRE AO CONHECIMENTO CIENTÍFICO}

A aparente estabilidade de que gozava o sistema de comunicação científica mundial foi abalada quando

\footnotetext{
* Veja a respeito, por exemplo, o artigo de TESTA, James. A base de dados ISI e seu processo de seleção de revistas. Ci. Inf. [online]. 1998, vol.27, no.2 [cited 05 April 2006], p.nd-nd. Disponível em: $<$ http://www.scielo.br/scielo.php?script=sci_arttext $\&$ pid $=S 0100$ $9651998000200022 \& \operatorname{lng}=\mathrm{en} \& n r m=i s o>\operatorname{ISSN} \mathbf{0 1 0 0}-1965$. Acesso em 5 de abril de 2006; e também, sobre as controvérsias que o ISI tem despertado: MONASTERSKY, Richard. The Number That's Devouring Science. The Chronicle of Higher Education. Section: Research \& Publishing v. 52, n. 8, p.: A12 Disponível em http:// chronicle.com. Acesso em 6 de abril de 2006.
}

estourou a chamada crise dos periódicos, em meados da década de 1980, que já vinha se anunciando desde a década de 70. O gatilho da crise foi a impossibilidade de as bibliotecas universitárias e de pesquisa americanas continuarem a manter suas coleções de periódicos e a corresponder a uma crescente demanda de seus usuários, impossibilidade decorrente da falta de financiamento para a conta apresentada pelas editoras, cada ano mais alta, mais alta mesmo que a inflação e outros índices que medem a economia. Isso já vinha acontecendo nos países em desenvolvimento, inclusive no Brasil, cujas bibliotecas já não conseguiam manter suas coleções atualizadas, mas a crise só detonou quando atingiu as universidades norte-americanas.

Quando estourou a crise, novas alternativas para os periódicos científicos foram procuradas. $\mathrm{O}$ estado de desenvolvimento da tecnologia de informação na época permitia antever muitas possibilidades, quase sempre suprimindo as editoras do processo. Essas alternativas começam a ganhar espaço nas discussões acadêmicas nos últimos anos da década de 80 e no início de década de 90 . Um artigo que marcou época, Scholarly Skywriting and the Prepublication Continuum of Scientific Inquiry, de Stevan Harnard (1991), preconizava skywriting - escrever nos céus, uma expressão que ele criou para exprimir sua visão de futuro: ele previa que "a disseminação da palavra escrita na 'Era Pós-Galáxia de Gutenberg' seria como escrever no céu, para todo mundo ver e adicionar seus comentários como se fosse grafite nos banheiros públicos", mas em uma escala galáctica (Harnard, 1998). Também por essa época começam a surgir iniciativas concretas de acesso livre a textos acadêmicos. Uma das mais bem-sucedidas dessas iniciativas foi o arquivo de pré-prints montado em Los Alamos, em 1991, por Paul Ginsparg, que, de acordo com artigo publicado na seção "Debates" da revista Nature em 2002 (portanto já com alguma perspectiva histórica), teria transformado a natureza e o alcance da informação científica em física e outras áreas. Ginsparg iniciou um sistema eletrônico no Laboratório Nacional de Los Alamos, Novo México, Estados Unidos, que permitia que pesquisadores da área de física e outras áreas relacionadas, localizados em qualquer parte do mundo, enviassem seus trabalhos para um repositório central, de onde poderiam ser recuperados por outros pesquisadores interessados. Na maioria dos casos tais trabalhos não haviam sido avaliados, mas o sistema verificava alguns pontos para garantir uma qualidade mínima (por exemplo, filiação do autor). Os autores enviavam seus preprints para Los Alamos, ao mesmo tempo que os submetiam às editoras. Cada dia, o sistema comunicava por correio eletrônico aos seus assinantes quais trabalhos 
haviam sido depositados, e, no caso de interesse, o assinante recebia, também por correio eletrônico, uma cópia do trabalho (LEVY, 2006). Hoje, esse serviço está instalado em Michigan.

\section{NOVAS FORMAS DE PUBLICAÇÃO E ACESSO À PESQUISA}

Os primeiros periódicos eletrônicos também começaram a aparecer nessa década de 90*, juntamente com outras iniciativas que utilizavam o meio eletrônico, algumas das quais deram origem a novas formas de publicação eletrônica e acesso à pesquisa, inclusive os de acesso aberto. Björk (2005) classifica os canais mais importantes existentes hoje para o acesso aberto em quatro tipos, listados e descritos a seguir:

- periódicos científicos eletrônicos com avaliação prévia pelos pares;

- servidores de e-prints para áreas específicas repositórios para assuntos específicos;

- repositórios institucionais de universidades específicas;

- auto-arquivamento em páginas pessoais dos autores.

Os periódicos eletrônicos de acesso livre começaram a aparecer no início da década de 90. São, em sua maior parte e assim como a grande maioria dos periódicos eletrônicos por assinatura, muito semelhantes, em aparência, ao modelo tradicional de periódico, com a importante diferença de serem acessíveis sem pagamento. Significam um ganho para o pesquisador em termos de acesso, conforto e presteza, mas não tanto em inovação, quando se considera a potencialidade do meio. Alguns títulos mantêm apenas a versão eletrônica para minimizar custos, e outros oferecem também uma versão impressa, paga. Recentemente surgiu uma nova modalidade de financiamento do acesso livre, via autor. Nessa modalidade, o autor (ou sua instituição) paga ao editor para que seu artigo possa ser acessado livremente. Em alguns casos, no entanto, o preço cobrado do autor é muito elevado**. Outra modalidade, adotada por alguns

* The Online Journal of Current Clinical Trials (com avaliação pelos pares) foi o primeiro periódico eletrônico a ser indexado no Index Medicus.

** A taxa cobrada pela Royal Society de Londres (Reino Unido) para permitir acesso livre imediato aos artigos publicados em seus periódicos (após publicação impressa) varia ente $£ 200$ a $£ 300$, o equivalente a US $\$ 370$ a US $\$ 550$. Outras editoras cobram menos: a Public Library of Science, (americana), cobra US $\$ 2,500$ por artigo. (Society tries open access The Scientist, magazine for the life sciences, 22nd June 2006. Disponível em: http://www.the-scientist.com. Acesso em 23 de junho de 2006). periódicos bastante conceituados como o New England Journal of Medicine, permite acesso livre após decorrido um período desde a publicação impressa, geralmente de seis meses a um ano. (Willinsky, 2003).

Os repositórios especializados em assuntos específicos são do tipo daquele já mencionado, sobre física, fundado em Los Alamos por Ginsparg, em 1991. De acordo com Björk (2005), seu objetivo é disponibilizar textos que são apresentados em eventos e outros canais paralelos aos periódicos tradicionais e também artigos submetidos, mas ainda não publicados em periódicos tradicionais (quando permitem essa divulgação antecipada). Os próprios autores depositam seus textos, barateando os custos de manutenção. Os responsáveis pelos repositórios têm a tarefa de evitar que material irrelevante seja depositado. Ainda de acordo com Björk, para áreas do conhecimento em que o ritmo de renovação é muito rápido, esta solução tem sido considerada bem atraente.

Os repositórios institucionais reúnem documentos produzidos na instituição. Por exemplo, repositórios de uma universidade reuniriam toda a produção científica ou acadêmica produzida na universidade, em forma digital, formando coleções de documentos digitais. Os mantenedores dos repositórios assumem então a responsabilidade de preservá-los, atribuindo-lhes, portanto, funções de memória institucional, mas a função principal é aumentar a visibilidade da instituição, permitindo e estimulando o acesso à produção da universidade. Os repositórios são abertos a todos os interessados, oferecendo meios de busca, identificação e recuperação. Todo tipo de documento produzido na universidade seria depositado no repositório universitário, como trabalhos dos professores e pesquisadores apresentados em congressos e reuniões profissionais, versões de artigos impressos, relatórios de pesquisa, programas de disciplinas e textos elaborados para aulas, trabalhos elaborados por alunos, teses e dissertações, trabalhos de disciplinas e outros.

Quanto às páginas individuais, de acordo com Björk (2005), elas existem desde os primeiros dias da Rede, sendo utilizadas pelos pesquisadores para divulgar sua produção pessoal. Ainda segundo Björk, embora não haja estatísticas, esse seria hoje o canal mais difundido de acesso aberto ao conhecimento acadêmico.

Considerando os quatro tipos de canais para o acesso aberto descritos acima, parece que a maior novidade e talvez o maior potencial para desenvolvimento estariam nos repositórios institucionais, que de certa forma 
disciplinam e sistematizam a atividade do arquivamento individual. Tais repositórios chamam a atenção pela obviedade (tardiamente percebida) da solução que apresentam para países em desenvolvimento. As comunidades científicas e cada autor membro dela, independentemente de situação de desenvolvimento científico de seu país, têm as mesmas aspirações quanto a atingirem maior visibilidade, reconhecimento, citações. Para isso, de acordo com a tradição tão profundamente inculcada em cada pesquisador durante o seu processo de formação, todos seus esforços são dirigidos para publicar, especialmente nas revistas mais prestigiosas, geralmente internacionais e indexadas. No Brasil, como em muitos outros países, esses esforços são estimulados e premiados pelas universidades e agências de fomento. Nem sempre, no entanto, os esforços têm sucesso. Uma alternativa extremamente atraente, mas certamente utópica, poderia ser oferecida, se todas as universidades do mundo mantivessem repositórios institucionais de acesso livre. Teríamos todos acesso a tudo.

Para países em desenvolvimento, como o Brasil, a questão do acesso ao que é publicado nas melhores revistas, mesmo quando o autor é brasileiro e membro de uma universidade local, é especialmente difícil e perversada. Aqui, como na maioria daqueles países, é o Estado que financia a educação dos novos cientistas, desde seu início até a obtenção dos graus mais altos, seja em instituição nacional ou estrangeira. Uma vez formado e já pesquisando, normalmente em uma universidade também mantida pelo Estado, sua pesquisa é freqüentemente financiada pelas agências de fomento federais ou estaduais, vale dizer, de novo, dinheiro público. Terminada a pesquisa, sua divulgação em reuniões e congressos será de novo financiada pelo Estado. Finalmente, a publicação em revista indexada poderá também receber auxílios dos cofres públicos, pois em algumas áreas as editoras cobram dos autores por página publicada. Ao publicar em uma revista, é hábito o autor ceder às editoras o direito autoral sobre o artigo. Uma vez publicada, entra em cena de novo o Estado, financiando as bibliotecas para sua compra.

\section{ACEITAÇÃO DAS PUBLICAÇÕES ELETRÔNICAS DE ACESSO LIVRE}

Essas iniciativas pioneiras não foram, de início, recebidas como formas legítimas de certificação da ciência e comunicação científica. Nas primeiras propostas que foram feitas, ainda na década de 90 , vislumbrava-se um mundo novo, mais democrático, no qual seria, se não eliminado, pelo menos bastante diminuído o poder das editoras e dos avaliadores (membros da elite). Mas foram exatamente esse dois pontos os maiores empecilhos para sua aceitação. A legitimidade foi negada às publicações eletrônicas porque prevalecia a crença de que apenas à publicação nos moldes tradicionais poderia ser atribuída autoridade para validação do conhecimento científico. No centro da questão, está o sistema de avaliação pelos pares.

O sistema de avaliação sempre foi alvo de muitas críticas e até hoje não faltam propostas de mudança. No entanto, nunca houve uma proposta que fosse considerada melhor do que o atual sistema. A "verdade científica" é produto de consenso, permanentemente sujeita à retificação. A comunidade científica delega a tarefa de julgamento a um grupo pequeno de especialistas, os nossos pares "encarregados do discurso científico" de que fala Lyotard. Apesar de estar longe de um modelo ideal, o atual sistema de avaliação prévia dos artigos é tido como absolutamente necessário para garantir a qualidade e confiabilidade dos textos publicados. A avaliação se dá quando o autor submete seu trabalho para publicação em uma revista. Poder-se-ia dizer, portanto, que, sem as revistas científicas e os rituais de avaliação que elas organizam e sustentam, sem a participação dos "grandes" de que falam Fourez (1995) e Cole (1983), não haveria avanço da ciência (pelo menos do que entendemos hoje como ciência), nem tampouco divulgação ou possibilidade de acesso ao conhecimento científico. Esse é o discurso que prevalece, nossa crença, e, apesar de tantas falhas, consideramos o atual sistema de avaliação prévia como mais adequado, correto e justo e, portanto legítimo, como diz Tyler (2006), do que as novas propostas.

E não faltaram propostas. Com o advento das tecnologias eletrônicas de comunicação pensava-se poder "democratizar" a avaliação dos textos submetidos à publicação, ampliando o número de avaliadores, pois cada leitor, isto é, um cientista ou pelo menos um estudioso do assunto, poderia, potencialmente, ser um avaliador. Ao mesmo tempo, esperava-se encurtar o tempo entre conclusão da pesquisa e divulgação de resultados. Um dos gargalos do processo tradicional de divulgação é a avaliação pelos pares. A comunicação eletrônica oferece como um de seus grandes atrativos a velocidade, que, quando comparada à morosidade do processo da publicação impressa, torna o meio eletrônico ainda mais atraente. Assim, várias propostas foram feitas para reformar o processo, como, por exemplo, a avaliação posterior à publicação, chamada comentários pelos pares (peer commentary), na qual não apenas aqueles 


\section{Suzana Pinheiro Machado Mueller}

especialistas "legitimados" iriam avaliar os textos, mas todos os que por ele se interessassem. Estaria sendo explorada a capacidade do meio eletrônico de permitir adicionar comentários e correções ao texto originalmente publicado. Alguns periódicos foram de fato criados de acordo com esse modelo ou adotando o comentário além da avaliação prévia, e não apenas sobreviveram como tiveram sucesso, tais como Current Anthropolgy, Behavioral and Brain Sciences e Psycoloquy (os dois últimos editados por Stevan Harnard).

Relembrando a crise dos periódicos, as propostas de adoção dos periódicos eletrônicos e a exposição dos artigos ao escrutínio de tantos avaliadores (chamados comentaristas) quantos se interessassem por ele pareciam a óbvia solução para os problemas enfrentados pelas bibliotecas universitárias e pelos pesquisadores. Mas a força da crença na avaliação prévia foi tremendamente subestimada. Parece estar claro, hoje, que qualquer iniciativa de publicação científica que não garanta avaliação prévia dos conteúdos por especialistas vai encontrar muitas barreiras para ser "legitimada" no mesmo nível dos periódicos tradicionais. Por mais atraentes que fossem, prometendo democratização, transparência e velocidade, as propostas para modificação da prática de avaliação pelos pares nunca conseguiram aprovação, jamais foram legitimadas.

Retomando as definições de legitimação e legitimidade apresentadas no início deste trabalho e considerando a questão da avaliação prévia, nota-se conformidade em todos os níveis de estratificação da comunidade científica, decorrente da crença profundamente estabelecida de que o sistema, apesar dos defeitos, é correto e adequado. A crença de que a avaliação pelos pares é necessária e melhor alternativa possível hoje é compartilhada até mesmo por Stevan Harnard (1998), um dos pioneiros e maiores defensores do acesso livre e da eliminação de qualquer barreira que impeça ou dificulte esse acesso, que assim se expressou:

... comentários pelos pares [peer commentary] não servem como substitutos para avaliação pelos pares. [.... N Não, comentários pelo pares é um complemento superbo à avaliação pelo pares, mas certamente não a substitui.

\section{O PAPEL DAS EDITORAS}

Com relação ao papel das editoras comerciais no processo, tais editoras são empresas poderosas, não só financeiramente, mas também politicamente, pois na medida em que são donas dos periódicos e detentoras dos copyrights dos trabalhos que esses periódicos publicam, controlam, de fato, o sistema de comunicação científica. Além disso, as editoras mais conceituadas ainda derivam poder justamente desse prestígio que lhes é atribuído pela comunidade. $\bigcirc$ discurso das editoras, ao não permitir acesso livre, é que elas protegem o autor e a integridade do texto.

Mas certamente há um conflito de interesses. Harnard (1998) é bastante enfático sobre esse ponto, argumentando que o autor não teme roubo do texto (como temem as editoras), mas sim das idéias, de plágio. Wiilinsky (2002) também mostra que os cientistas e acadêmicos não compartilham do mesmo ponto de vista ou interesses dos editores dos periódicos em que publicam seus trabalhos. Para as editoras, o retorno financeiro vem das vendas. Para os cientistas, o retorno financeiro é indireto e vem do reconhecimento e da reputação que resulta da publicação e que então se traduz em aumento de salário, promoções, convites pagos para dar palestras, contratos como consultores, bolsas e auxílios para pesquisa, por exemplo.

Reforçando as idéias de Harnard, Willinky (2002) argumenta que no caso do periódico científico, os interesses das editoras e dos autores divergem completamente: o interesse dos pesquisadores no copyright é assegurar que seus trabalhos sejam de fato reconhecidos como seus quando reproduzidos ou citados, que o crédito lhes seja dado, mas não impedir que sejam reproduzidos e lidos. $\mathrm{O}$ autor espera que o direito autoral o proteja contra plágio e citação de seu trabalho sem o reconhecimento de crédito, não contra acesso ou reprodução do texto. Enquanto para as editoras, o importante é resguardar o direito de acesso apenas para os que pagam. Ao contrário do esperado, conclui Willinsky, a prática vem mostrando que o meio eletrônico oferece às editoras condições de controle de acesso ainda melhores que o meio impresso.

As possibilidades e potencialidades das publicações eletrônicas, desde quando surgiram, não passaram despercebidas pela editoras, que desde logo compreenderam o perigo e as oportunidades que elas representavam para sua sobrevivência e atuação no sistema de comunicação científica e se prepararam para isso. Programaram e executaram um plano de transição para o meio eletrônico que envolve, na maioria dos casos, edição em meio eletrônico e impresso, ambos com acesso via assinatura paga. Parece ter havido entendimento entre as autoridades legitimadas das comunidades científicas e as editoras, nessa transição. $\bigcirc$ modelo 
tradicional foi mantido no novo meio. Talvez devêssemos considerar que o sistema de avaliação prévia, colocado em prática e controlado pelas elites de cada área, necessita do suporte e infra-estrutura garantidos pelas editoras. $\mathrm{O}$ fato é que, hoje, dentre as diversas modalidades de divulgação de textos acadêmicos e científicos que estão disponíveis na Internet, pode-se dizer que o grau de legitimação (credibilidade equivalente ao periódico tradicional) avançou exatamente nas modalidades em que as editoras continuam presentes e detendo o copyright. Nesses casos, apesar da migração ou duplicação dos títulos de periódicos para o meio eletrônico, a estrutura existente para o meio impresso parece ter sido mantida. A necessidade de pagamento, para que o usuário tenha acesso, continua valendo para a maioria dos títulos mais prestigiados. As bibliotecas não se livraram das contas altas de renovação de assinaturas e ainda perderam o direito de acesso aos fascículos pelos quais já haviam pago. Hoje pagam pelo acesso que vale pelo período coberto pela assinatura, não pelo objeto. A utopia do acesso livre, do skywriting de Harnard, não se confirmou da forma como foi sonhada, pelo menos até agora.

Em contrapartida, as editoras vêm cedendo aos poucos à pressão pelo acesso livre, mas impondo certas condições. Um fator que parece estar contribuindo para a mudança de atitude é a evidência obtida por alguns estudos de que as citações para textos eletrônicos ocorrem em números mais altos (para algumas áreas) que as citações para textos impressos (Harnard; Brody, 2004; The Impact... 2004). Esse fato parece estar também estimulando autores a submeter seus textos para publicação em revistas eletrônicas de acesso livre, o que pode estar influenciando, indiretamente, as editoras a flexibilizar seu controle sobre o acesso aos textos que publicam. $O$ ganho para as editoras viria do fato de que maior número de citações leva a maior fator de impacto. A publicação eletrônica de livre acesso parece estar recebendo um volume significativo de citações, e isso é interessante para as editoras, pois citações elevam prestígio, e isso se traduz em mais vendas e ainda mais prestígio.
O quadro a seguir, elaborado por Willinsky (2003), mostra diferentes modalidades de acesso livre que estavam sendo oferecidas em 2003. É interessante notar, nesse quadro, como as editoras comerciais estão avançando (ou cedendo) na idéia de acesso livre, como, por exemplo, facilitar o acesso para países mais pobres ou permitir o acesso aos artigos seis meses após a primeira publicação.

\section{DISCUSSÃO}

Este texto teve como seu foco principal o movimento de acesso livre ao conhecimento científico. Mas focalizou também as publicações eletrônicas científicas, pois são elas que permitem a idéia e a implementação do conceito de acesso livre. Primeiro, as publicações eletrônicas têm de ser aceitas. Então, torna-se possível o movimento pelo acesso livre. Vimos que a comunidade científica, ao longo da história das publicações eletrônicas, tem se mostrado reticente quanto à plena aceitação, tanto dos periódicos eletrônicos em geral, quanto daqueles de acesso livre.
FIGURA 1

Tipos de arquivos de acesso aberto

\begin{tabular}{|c|c|c|}
\hline \multicolumn{3}{|c|}{ Tipos de arquivos e periódicos de acesso aberto } \\
\hline Tipo de acesso & Descrição & $\begin{array}{l}\text { Exemplo de } \\
\text { Periódico ou portal }\end{array}$ \\
\hline E-print Archives & $\begin{array}{l}\text { Autores depositam preprints e/ou } \\
\text { postprints em arquivos abertos. }\end{array}$ & $\begin{array}{l}\text { arXiv.org.Eprint } \\
\text { Service }\end{array}$ \\
\hline $\begin{array}{l}\text { Unqualified } \\
\text { (Acesso universal) }\end{array}$ & $\begin{array}{l}\text { Publicação imediata e completa } \\
\text { de periódico em arquivo aberto }\end{array}$ & First Monday \\
\hline $\begin{array}{l}\text { Dual Mode } \\
\text { Modo duplo }\end{array}$ & $\begin{array}{l}\text { São oferecidas duas versões do } \\
\text { periódico: assinatura paga para a } \\
\text { versão impressa e acesso aberto } \\
\text { para versão eletrônica. }\end{array}$ & $\begin{array}{l}\text { Journal of } \\
\text { Postgraduate } \\
\text { Medicine }\end{array}$ \\
\hline $\begin{array}{l}\text { Delayed AO } \\
\text { (Acesso livre atrasado) }\end{array}$ & $\begin{array}{l}\text { O acesso aberto se torna } \\
\text { disponível alguns meses após a } \\
\text { publicação inicial, paga. }\end{array}$ & $\begin{array}{l}\text { New England Journal } \\
\text { of Medicine }\end{array}$ \\
\hline $\begin{array}{l}\text { Author Fee } \\
\text { Autor paga taxa }\end{array}$ & $\begin{array}{l}\text { Autores pagam às editoras um } \\
\text { taxa para compensá-las pelo } \\
\text { acesso aberto. }\end{array}$ & Bio-Med Central \\
\hline $\begin{array}{l}\text { Partial AO } \\
\text { (Acesso livre parcial) }\end{array}$ & $\begin{array}{l}\text { Alguns ar tigos em um fascículo } \\
\text { são de acesso aberto. }\end{array}$ & $\begin{array}{l}\text { New York Review of } \\
\text { Books }\end{array}$ \\
\hline $\begin{array}{l}\text { Com bases em renda } \\
\text { per capita }\end{array}$ & $\begin{array}{l}\text { Acesso aberto é concedido para } \\
\text { determinados países com renda } \\
\text { per capita baixa. }\end{array}$ & $\begin{array}{l}\text { HINARI (World } \\
\text { Health Organization } \\
\text { - Organização } \\
\text { Mundial da Saúde) }\end{array}$ \\
\hline $\begin{array}{l}\text { Abstract } \\
\text { (Resumo) }\end{array}$ & $\begin{array}{l}\text { Acesso aberto apenas aos } \\
\text { sumários e resumos. }\end{array}$ & ScienceDirect \\
\hline $\begin{array}{l}\text { Co-op } \\
\text { (Cooperativas) }\end{array}$ & $\begin{array}{l}\text { Membros da instituição sustentam } \\
\text { periódicos de acesso aberto }\end{array}$ & $\begin{array}{l}\text { German Academic } \\
\text { Publishers (GAP) }\end{array}$ \\
\hline
\end{tabular}

Fonte: Willisnky 2003. (adaptado) 


\section{Suzana Pinheiro Machado Mueller}

Retomando os conceitos de legitimação e legitimidade apresentados no início deste trabalho, poderíamos perguntar até que ponto as publicações eletrônicas científicas em geral e aquelas de acesso livre conseguiram vencer as barreiras da tradição e outros interesses, rumo à legitimidade na crença dos pesquisadores e nas práticas da pesquisa e comunicação científica.

Para responder à questão, precisamos entender a comunidade científica não só como uma organização social complexa, hierárquica, norteada por princípios e crenças tradicionais, mas também como um contexto em que há vários interesses em jogo. A comunidade se insere em uma sociedade maior, da qual faz parte. As crenças que a norteiam, profundamente estabelecidas, são estimuladas não apenas pela tradição, mas também por interesses de segmentos da própria comunidade e de fora dela, interesses que parecem estar conformando o rumo das publicações eletrônicas.

Hoje, periódicos eletrônicos são uma realidade já tornada banal e aceita. Lembrando Zelditch (2001, p. 9), legitimação é o processo que conforma o inaceitável às normas, valores, práticas e procedimentos aceitáveis, dependendo, portanto, do consenso. As publicações eletrônicas são hoje consideradas legítimas, mas apenas quando seguem os modelos tradicionais do periódico impresso. As demais, aquelas que propõem modelos inovadores, embora já não mais totalmente inaceitáveis, também não parecem ter sido elevadas ao nível de completa legitimação ou igualdade.

Retomando o conceito de Lyotard, não parece haver indícios de que o "legislador" encarregado de zelar pelo discurso científico irá modificar de maneira significativa, em futuro próximo ou mesmo de médio prazo, as condições que determinam se uma afirmação pode ser considerada conhecimento científico. Nesse ponto, o consenso parece claro e tudo indica que o sistema de avaliação prévia permanecerá ainda por muito tempo. Parece que não atingimos consenso ainda na maneira como o conhecimento, uma vez avaliado, pode se tornar acessível a todos. Entre as modalidades propostas, o movimento de acesso aberto vem ganhando terreno e parece estar atraindo adeptos importantes.

Ainda que lentamente, vêm surgindo, tanto nos países em desenvolvimento, quanto em países desenvolvidos, indicadores favoráveis ao movimento de acesso aberto. Desde o encontro pioneiro que ficou conhecido como Budapest Open Access Initiative, ocorrido em dezembro de
2001, outros se seguiram, ampliando o movimento*. Vários países, tais como o Reino Unido e mais recentemente os Estados Unidos, entre outros, estão discutindo e implementado formas legais de condicionar a concessão de financiamento público à pesquisa ao depósito dos resultados em repositórios de acesso aberto, independentemente de sua publicação em outros canais**.

No Brasil, o sucesso do Portal de Periódicos da Capes atesta a aceitação do meio eletrônico para os periódicos, pelo menos para aqueles que seguem o modelo bem próximo do tradicional impresso. Além disso, as diversas iniciativas do Ibict e do MEC que incluem acesso aberto e a aceitação pelas nossas agências de fomento (Capes e $\mathrm{CNPq}$ ) de publicações em periódicos eletrônicos como equivalentes às publicações em periódicos tradicionais (para fins de avaliação de cursos e curriculum vitae) também são indicadores significativos de um processo de aceitação e legitimação.

O movimento pelos repositórios institucionais, especialmente nas universidades, é outro indicador importante de aceitação. Nesses repositórios, são depositadas ou declaradas aceitáveis para depósito, várias modalidades de documentos e conteúdos, além de artigos ou resultados de pesquisa, mas sua aceitação ou a existência de planos para sua implementação representa marco importante para o movimento de acesso aberto.

\footnotetext{
* Bethesda Statement on Open Access Publishing, June 20, 2003 http://www.earlham.edu/ peters Berlin Declaration on Open Access to Knowledge in the Sciences and Humanities, October 22, 2003. http://www.zim.mpg.de/openaccess-berlin UN World Summit on the Information Society Declaration of Principles and Plan of Action, December 12, 2003 http://www.itu.int - Document 1 http://www.itu.int - Document 2 Organisation for Economic Co-operation and Development (OECD) Declaration on Access to Research Data From Public Funding, January 30, 2004 http://www.oecd.org The International Federation of Library Associations and Institutions (IFLA) released the IFLA Statement on Open Access to Scholarly Literature and Research Documentation, February 24, 2004. http:// www.ifla.org (Budapest Open Access Initiative, 2006).

** Veja por exemplo: Nos Estados Unidos: SOME Publishers of Scholarly Journals Dislike Bill to Require Online Access to Articles. Disponível em: http://www.nytimes.com/2006/05/08/business/media/ 08journal. html? r=1\&oref=slogin Acesso em 10 de maio de 2006; No Reino Unido: Pincock, Stephen. UK research to be open access. Disponível em: 2006.http://www.the-scientist.com/news [Published 28th June 2006 07:26 PM GMT] Acesso em: 28 de junho de 2006.
} 


\section{CONSIDERAÇÕES FINAIS}

O que temos pela frente é de fato um enorme desafio, em cujo cerne se situa o processo de legitimação das publicações eletrônicas como elementos reconhecidos no sistema de comunicação cientifica. A legitimidade já parece ter sido atribuída aos periódicos eletrônicos que seguem o modelo tradicional. Mas há possibilidade de muito mais, como se pode vislumbrar nos movimentos de acesso aberto e nos repositórios institucionais. Formas totalmente novas de comunicação estão sendo propostas e testadas. Mas, sem legitimação, sem o consenso da comunidade, nenhuma proposta terá efeito ou chances de provocar mudanças significativas no atual sistema de comunicação científica, não importa o quão inovadora ou o quão formidável sua contribuição potencial. Examinando as barreiras que dificultam a proliferação dessas iniciativas, especialmente do movimento pelo acesso aberto, Björk (2004) chega à conclusão de que não há, em nenhum dos atores envolvidos no processo, incentivo real para a completa aceitação do acesso livre.

As palavras de Björk (2004) parecem retratar o momento atual com realismo:

Apesar de a maioria de pesquisadores concordarem com a idéia do acesso livre e acreditarem que sua adoção traria vantagens para a ciência, fazê-los aderirem ao movimento é como tentar fazer as pessoas se comportarem de uma maneira mais ecológica. Apesar de a maioria das pessoas reconhecerem que é preciso economizar energia e reciclar o lixo, é preciso muito mais do que isso para fazê-las mudar de hábito. Será preciso uma combinação de medidas de diversos tipos, tais como construir uma infra-estrutura para a disposição do lixo, estabelecer legislação e cobranças de taxas e multas para provocar mudanças significativas de comportamento.

Esse mesmo autor pensa ter havido um amadurecimento do "espírito iconoclasta", que motivou os pioneiros do movimento pelo acesso aberto, e que agora se estaria buscando alternativas mais realistas que levam em conta modelos econômicos sustentáveis. A questão econômica é vista por ele como central, cabendo a responsabilidade pela decisão aos atores do processo de comunicação, "tanto do lado do suprimento, quanto do lado da demanda".

Há pouco mais de 10 anos alguns acreditaram em uma rápida revolução no sistema tradicional de comunicação científica, uma completa democratização do acesso e das funções de julgamento, uma utopia. Embora não tenha ocorrido como foi sonhado, as iniciativas que têm sido discutidas na literatura, nas universidades e nos parlamentos e também no mundo das editoras sinalizam, a meu ver, para a formação de um consenso ou entendimento que levará à legitimação, talvez em vários níveis de confiabilidade e para vários propósitos, das iniciativas de comunicação científica eletrônica de acesso aberto.

\section{REFERÊNCIAS}

ANTELMAN, Kristin. Do Open-Access Articles Have a Greater Research Impact? College and Reseach Libraries. September 2004 p.:372. 382 Disponível em: http://www.ala.org/ala/acrl/acrlpubs/crljournal/ crl2004/crlseptember/antelman.pdf. Acesso em 14 de abril de 2006.

BISSOT, Hughes. La transparence sacrée ou le secret révélé : le principe dialogique comme mode de légitimation du pouvoir.Université de Paris-1 Panthéon-Sorbonne. Janvier 2002. Disponível em: http:// www.dhdi.free.fr/recherches/etudesdiverses/articles/bissot.pdf. Acesso; 15 abril 2006

BJÖRK, B-C. (2004) Open access to scientific publications - an analysis of the barriers to change Information Research, 9 (2) paper 170. Disponível em: http://InformationR.net/ir/9-2/paper170.html] Acesso: 10 abril 2006.

BUDAPEST OPEN ACCESS INITIATIVE. Disponível em: http:// www.soros.org/openaccess/initiatives.shtml. Acesso: 8 maio 2006.

COLE, Stephen, The Hierarchy of the Sciences? The American Journal of Sociology, vol. 89, n.1 Jul 1983, p.:111-139. Disponível em: http:// links.jstor.org/sici?sici $=0002-9602 \% 28198307 \% 2989 \% 3$ A111\%3\% ATHOTS\%3E2.0CO\%3B2-H Acesso em 4 de 4 de 2006.

FOUREZ, Gerard. A construção das ciências: introdução à filosofia e à ética das ciências. São Paulo: Editora da UNESP, 1995. p.95+.

HARNAD, S. Learned inquiry and the net: the role of peer review, peer commentary and copyright. 1998. Revised expanded draft for Learned Publishing 11(4) 1998 pp. 183-192 of: Snider Visiting Professorship, Keynote Address, "Learned Inquiry and the Net," Beyond Print: Symposium on Electronic Publishing and New Models of Scholarly Communication, Center for Instructional Technology, University of Toronto at Scarborough, Development, September 26-27, 1997.Disponível em: http://eprints.ecs.soton.ac.uk/2633/02/ harnad98.toronto.learnedpub.html. Acesso em 10 de abril de 2006.

HARNAD, S. Scholarly Skywriting and the Prepublication Continuum of Scientific Inquiry. Psychological Science 1: $342-343$ (reprinted in Current Contents 45: 9-13, November 11 1991. Disponível em: ftp:// ftp.princeton.edu/pub/harnad/Harnad/HTML/ harnad90.skywriting.html. Acesso em 10 de Abril 2006

HARNARD, Stevan; Brody, Tim. Comparing the Impact of Open Access (OA) vs. Non-OA Articles in the Same Journals. D-Lib Magazine v.10, n.6. June 2004. Disponível em: http:// webdoc.sub.gwdg.de/edoc/aw/d-lib/dlib/june04/harnad/06harnad.html ou http://www.dlib.org/dlib/june04/harnad/06harnad.html. Acesso: 14 de abril de 2006.

LEGITIMATION. In: ENCYCLOPEDIA OF MARXISM. Marxists Internet Archive (marxists.org), 19939-5005 Disponível em: http:// www.marxists.org/glossary/terms/l/e.htm. Acesso em 3 abril de 2006

LEVY, Dawn. Physicists thrive with paperless publishing. Disponível em www.stanford.edu/dept/news/pr/00/000223paperlesspub.html Acesso em 7 de abril de 2006).

LYMAN, Peter. Digital Documents and the Future of the Academic Community. Paper presented at the Conference on Scholarly communication and technology, organized by the Andrew W Mellon 


\section{Suzana Pinheiro Machado Mueller}

Foundation at Emory University, April 24-2 1997. Disponível em: http://www.arl.org/scomm/scat/lyman.html\#n4. Acesso 7 de abril de 2006)

LYOTARD, Jean-François The Postmodern Condition. Manchester : Manchester University Press, 1984. The First 5 Chapters of main body of work are reproduced here. Disponível em : http:// www.marxists.org/reference/subject/philosophy/works/fr/lyotard.htm Acesso em 24 junho 2006.

MEADOWS, A J. A Comunicação Científica. Brasília: Briquet de Lemos, 1999, p. vii.

NATURE Debates. 2002, Disponível em http://www.nature.com/ nature/debates/e-access/Articles/ginsparg.html) Acesso: 3 de abril de 2006.

SHAWVER, Lois, A study of Lyotard"s concept of Legitmation, as it is spelled out in the Postmodern Condition, working document 12/08/ 98. Disponível em http://users.california.com/ rathbone/legitima.htm Acesso em 2 abril 2006

THE IMPACT of open access journals: a citation study by Thomson ISI http://scientific.thomson.com/ts/media/presentrep/acropdf/impactoa-journals.pdf.
TYLER, Tom R. Annual Review of Psychology. v. 57: 375-400 (Volume publication date January 2006) (DOI:10.1146/ annurev.psych.57.102904.190038) Disponível em: http:// arjournals.annualreviews.org/doi/full/10.1146/ annurev.psych.57.102904.190038?cookieSet=1\#abstract. Acesso: 29 março 2006.

WILLINSKY, John. Copyright Contradictions in Scholarly Publishing. First Monday, v. 7, n. 11, November 2002. Disponível em: http:// firstmonday.org/issues/issue7_11/willinsky/index.html Acesso: 14 de abril de 2006.

WILLINSKY, John. The Nine Flavours of Open Access Scholarly Publishing. Journal of Postgraduate Medicine v.49, p.:263-267, 2003. Disponível em: http://www.jpgmonline.com/article.asp?issn $=0022$ $3859 ;$ year $=2003 ;$ volume $=49 ;$ issue $=3 ;$ spage $=263$; epage $=267$; aulast $=$ Willinsky, Acesso: 15 abril de 2006.

ZELDITCH, Morris. Processes of legitimation: recent developments and new directions. Social Psychology Quarterly, v.64, n.1, p.4-17, 2001. Disponível em: http:www.jstor.org/ Acesso:31 março 2006. 